\title{
Capacity Enhancement of Family Development Centre Staff in Early Childhood Language Learning
}

\author{
Warunsicha Supprasert ${ }^{1,2} \&$ Piyathida Khajornchaikul ${ }^{1}$ \\ ${ }^{1}$ Faculty of Public Health, Mahidol University, Bangkok, Thailand \\ ${ }^{2}$ Sirindhorn College of Public Health, Chonburi, Thailand \\ Correspondence: Piyathida Khajornchaikul, Faculty of Public Health, Mahidol University, Bangkok, Thailand. \\ E-mail: piyatida.kha@mahidol.ac.th
}

Received: July 18, $2021 \quad$ Accepted: July 26, $2021 \quad$ Online Published: July 31, 2021

doi:10.5539/ass.v17n8p23 URL: https://doi.org/10.5539/ass.v17n8p23

\begin{abstract}
This study aimed to identify effective plans using the Future Search Conference (FSC) approach to enhance the Thai Family Development Centre (FDC) staff in early childhood language promotion through good parenting. Data from, 55 stakeholders FDC staff, district and local health centres, Child Care Centres (CCCs), and local authorities from 10 villages of rural subdistricts in a central Thai province, Thailand, checked for correctness and analyzed using thematic analysis, alongside field notes from observations, worksheets, videotape records, and photo voice. Results revealed that applying FSC techniques created a common future and successfully helped participants to understand past situations clearly and factors related to the problem. Three key strategies emerged to enhance FDC staff capacity including 1) organising ongoing training workshops to enhance staff knowledge and skills needed to achieve effective work performance, 2) building teamwork and 3) developing staff morale for working.
\end{abstract}

Keywords: future search conference, capacity, language development, early childhood

\section{Introduction}

Language development is essential for children's future learning and intelligence. The high prevalence of delayed linguistic development is a concern for parents and professionals. Because of the long-term effects of language delay in terms of communication, social and emotional behaviour and future education of children; investing in children is so valuable that we should be aware of and take great care of any such opportunity (Sayre, Devercelli, Neuman, \& Wodon, 2015; Nopmaneejamruslert, 2013; Wake et al., 2012; James, 2015). Family is the first priority environment that is closest to children (Tran, Luchters, \& Fisher, 2016). Several Thai studies revealed that most parents, especially in rural families had inappropriate child rearing (Denduang et al., 2016). Therefore, educating parents and proper parenting should be a concern because it helps those parents understand and address the children's needs and lead to language acquisition problem solving (Medrano, Tabben, \& Toussaint, 2012).

Thai Family Development Centre (FDC) in the community, represents a public sector organisation, committee members are recruited from representatives of local groups or community organisations, for instance, Village Health Volunteers (VHV), community leaders, Subdistrict Administration Organisation (SAO) members and so on. The FDC's mission includes surveying and analysing family data, planning and organising activities to transfer knowledge to families, as well as coordinating with all relevant sectors to strengthen the family institution. And The FDC is a necessary social capital considered as an excellent linkage between the family members and the community unit (Cheepsumon \& Boonmak, 2014). According to currently changing family circumstances, the FDC team essentially needs to be more proficient in supporting families and their children (McDonald, 2010). The literature reviews related to the FDC in the community also found that most committees lacked capacity development to prepare them to work effectively. Additionally, competency development training workshops provided for local FDC members and opportunity to access learning resources for self-development are lacking. As a result, most FDC staff have insufficient knowledge and understanding regarding their roles and fail to organise learning processes to strengthen families effectively (Cheepsumon, \& Boonmak, 2014; Maneerat, 2008). Thus, the existing potential of the FDC staff should be strengthened and developed to possess profound knowledge and experience to be able to work effectively regarding proper 
parenting promotion concerning preschool language development in the community (Maggi et al., 2005). Suphan Buri Province, a central rural province in Thailand, has been suffering from a high prevalence of child developmental delay (MOPH, 2015; Kanpirom, \& Masena, 2017). These results were in line with a pilot study in the same area revealing a suspiciously high level of delay (40.8\%), especially in the language area (34.2\%).

Regarding awareness of the problem, authors were interested in studying the implications of the Future Search Conference (FSC). This investigation employed a process that allowed attendees to be involved in the subject matter by bringing each other's experiences together to create a shared vision and develop group plans or guidelines (Janoff \& Weisbord, 2021; Sellnow, 2006). The present study aimed to describe how the FSC could be used as a method to plan FDC professional development and to identify and use the empirical data arising from the FSC approach as guidelines to enhance staff capacity in promoting early childhood language learning through good parenting.

\section{Materials Studied}

This qualitative research applied the FSC technique as a guideline for stakeholders to jointly develop a training program on developing FDC capacity that meets the needs and corresponds to the community context. The study was conducted in a subdistrict of Suphan Buri Province, in a central Thai province, Thailand. The subject area was affiliated with an area suffering from early childhood language deficiency (MOPH, 2015; Kanpirom \& Masena, 2017).

\subsection{Participants}

Purposive sampling was used as the selection method, conducted by analysing individuals in the research area who were stakeholders or involved in the issues being studied or "stakeholder analysis" (Schmeer, 1999). The 55 participants included 35 FDC staff, 5 public health officers responsible for child health in district health offices and Tumbol health promotion hospitals, 10 Child Care Centres (CCCs staff), 1 executive, 4 relevant staff in the Division of Social Welfare, Division of Education, and Division of Public Health and Environment of Rairot SAO. All of them were recruited based on the sampling frame criteria.

\subsection{Research Instruments}

The research instruments comprised: FSC plan and field recording tools, including a videotape recorder, digital camera, and non - participant observation form and activity worksheets. All research instruments were developed by the author based on relevant theories and research objectives which had been revised and approved by the Professor. Experts in social work, early childhood and family study and public health nursing assessed its accuracy, content validity and language usage.

The process of FSC consisted of three main components: 1) analysing past events to connect to current situations and trends. 2) analysing and synthesizing the current situation to understand the direction and factors influencing the main points of the meeting and 3) creating the desired future to jointly define common ground and create action plans to achieve a shared future. The FSC comprised 13 subactivities divided into three groups across time: past, present and future. Activity shown in Table 1. The author played the role as a facilitator and collaborator for all possible resources directed toward participant achievement of their goal. Attendees were divided in two subgroups. The term, "stakeholders", refers to the group wherein members share some characteristics. In this research, relevant stakeholders were divided by zones of public health service areas including Banchongpikul Health Promoting Hospital Zone (Villages 1, 2, 5, 6 and 8) and Rairot Health Promoting Hospital Zone (Village 3, 4, 7, 9 and 10). The term, "mixed group", refers to the group wherein members have a variety of statuses and responsibilities.

Table 1. The process of Future Search Conference, MSDHS. (2010)

\begin{tabular}{cll}
\hline Main components & \multicolumn{1}{c}{ Activities } & Participants \\
\hline \multirow{2}{*}{ Focus on the Past } & 1. Timeline & Mixed group \\
& 2. Understanding the past & Mixed group \\
& 3. Insight & Co - meeting \\
\hline \multirow{3}{*}{ Focus on the Present } & 4. Mind mapping & Stakeholders \\
& 5. Stakeholder's viewpoints & Stakeholders \\
& 6. Satisfaction \& Disappointment & Co - meeting \\
& 7. Synthesis & Stakeholders
\end{tabular}


8. Idea future scenario

9. Preforming role play

Focus on the Future
10. Common ground \& Possible idea

$$
\begin{aligned}
& \text { 11. Action plan } \\
& \text { 12. Action plan } \\
& \text { 13. Action plan }
\end{aligned}
$$

Stakeholders

Mixed group

Mixed group

Individual

Self- selected group

Stakeholders

This research obtained approval by the Mahidol University Research Ethics Committee. Information for participants decision-making, and then asked them to sign informed consent forms before taking part in the research.

\subsection{Data Collection and Data Analysis}

The process of FSC, 13 activities were recorded by using videotape. Observed and record the activities of participant by using observations, 9 worksheets of activities, and photo voice.

Data were employed from videotape records, and checked for correctness. The transcripts analysed using thematic analysis. The transcripts were read and coded, using an inductive approach to identify key themes and make connections between the ideas emerging using a simplified form of the constant comparative method. Later, the transcripts and a summary of provisional themes were returned to the interviewees for "respondent validation" and their comments were fed into the analysis. Data were completed alongside field notes from non-participatory observations, activity worksheets and photovoice.

\section{Results}

The results revealed that participants responded positively to the overall activities and exhibited enthusiasm, interest and cooperation in brainstorming to achieve the objectives in each subactivity. All members had the opportunity to express their opinions and to share their experiences and knowledge which created a pleasant atmosphere for learning. In addition, the top executives of SAO also paid considerable attention to the FSC activities. According to the random inquiry of participants' opinions regarding the satisfaction of the activities, most participants expressed that they were happy to participate in the meetings because they were extremely useful for professional development.

“...Events were enjoyable, and provide an opportunity to exchange ideas with stakeholders from other sectors that helped to understand and recognise problems..." (45 years old female, FDC)

\subsection{Results of Subactivities Following the 13 Steps of FSC}

a) Historical analysis

\subsubsection{Timeline (mixed group)}

Participants perceived the importance of past events related to challenges to language development, the role and potential of FDC team over the last ten years. All participants reflected on their experiences at ten, five, three and one years before. Significant events occurred as described below.

"Ten years ago, community members lacked awareness and did not pay attention to the importance of language development. Health professionals and child providers used the developmental assessment tools called, "Hygiene 49", which did not include details of a specific language. The FDC still had no role in promoting early language development."

"Five years ago, more families emphasised language development than ten years ago. However, they still lacked knowledge to promote language development. Thai Ministry of Public Health improved the quality of assessment tools and then changed the name of those tools to, "Health 55". No FDC activities were conducted aimed at promoting early childhood language development."

"Three years ago, CCC staff and other relevant agencies paid more attention to resolving problems. Thai government established a policy to use the Developmental Surveillance Promotion Manual (DSPM) as an assessment tool, which focused on language dimension classified in two parts including receptive and expressive language. FDC staff did not receive support for potential development due to a lack of training and fostering of morale regarding working."

"Over the past one year, parents exhibited inappropriate parenting practices such as declining communication 
within the family due to advances in technology. Child providers lacked continuous training. The FDC initiated pilot activities were implemented, but it did not cover all areas due to inadequate financial support."

\subsubsection{Understanding the Past (Mixed Group)}

Participants analyzed the relationship of data obtained from prior sub activity. Changes in developmental situation were caused by 1) socio-economic conditions, 2) parenting practice, 3) quality of CCCs staff, and 4) government policies regarding education, public health and welfare etc. The major obstacles gathered from group brainstorming was the capability of the FDC that remained limited and was performed inadequately. The issues that should be further developed to improve FDC staff performance included 1) knowledge and skills in language development, 2) project planning, and 3) teamwork and network building skills.

\subsubsection{Insight (co-meeting)}

Participants provided feedback and comments concerning the results of data analysis presented by each group as well as reflecting on what they had learnt from the past. One key issue raised for discussion was the lack of continued financial support for project implementation.

b) Analysis and synthesis of current situation

\subsubsection{Mind Mapping (Stakeholders)}

The data obtained on flip charts from sub activities 1 and 2 were presented as one big picture, where all members could see all the details. Participants shared, analysed and created an overview of trends and links between all factors. They proposed that the issues influencing FDC staff capacity consisted of three key issues including 1) personal factors (knowledge, attitudes, skills, morale in working, partnership networks and so on), 2) material factors (community learning resources and so on), and 3) budget factors (adequate and coverage budgetary support, appropriate remuneration and so on).

\subsubsection{Stakeholder's Viewpoints (Stakeholders)}

Participants selected the prioritised issues that had already been summarised and then they considered how to re-prioritise at the entire meeting. The viewpoints concerning the factors derived from mind mapping revealed that personal factors (knowledge and skills) influenced staff capacity. Further, teamwork building that provided an opportunity for greater success was important and ranked as first. The $2^{\text {nd }}$ priority constituted supportive factors such as budget, equipment, compensation and so on.

\subsubsection{Satisfaction \& Disappointment (Stakeholders)}

Participants in each group reviewed their past and present missions to better understand their existing situations, capabilities and limits in work performance. The key issues that they were proud of included 1) building teamwork, enjoying harmony, and achieving success in work, 2) sharing ideas with their team members 3) being involved in activities regularly, and 4) receiving trust from others. Issues that they were disappointed with comprised 1) lack of morale in working, 2) lack of parental involvement, and 3) lack of cooperation by related sectors.

\subsubsection{Synthesis (co-meeting)}

All participants reflected on their feelings in the manner of emotional sharing both regarding the issues that they were satisfied with in their assigned role and expressed sympathy, understanding and grievances concerning the issues of regret.

c) Creating desirable future

\subsubsection{Designing Role Plays (Stakeholders)}

Participants shared their thoughts on the desirable future of the community under the theme, "Creating a new generation of FDC". Participants in both stakeholder groups were divided by the responsibility zone of the subdistrict health promotion hospital. Each person drew a desirable future using beautiful colors. The desirable future of individuals was arranged as a storyboard and then presented as a short drama.

\subsubsection{Performing Role Plays (Stakeholders)}

Each group captured the attention of the audience by performing a role play with joyful, concrete and possible solutions in practice. The role play presented by group 1 emphasised on the importance of a multidisciplinary team and family network that worked through a pro-active approach. Group 2 focused on learning environment promoting language development. 


\subsubsection{Common Ground \& Possible Ideas (Mixed Group)}

Participants exchanged and explored the strategies to achieve a desirable future using the point of view and the content of the dramas, which each group had presented. The common ground that was voted upon and prioritised as important included 1) training on areas they needed, 2) collaboration and networking and 3) promoting motivation in working. Other possible ideas that were voted on and prioritised as important included 1) creating an innovation, 2) using the group process as a method for successful operations, and 3) earnest and regular practice.

\subsubsection{1-13 Action Plans of Individuals, the Self-Selected Group, Stakeholders}

All participants chose an issue that they were interested in and appreciated. Most FDC staff were interested in quality teamwork development to improve their knowledge and skills in terms of coordinating with health sectors and related agencies. They considered the status quo, strategies/guidelines and activities/steps to cooperatively improve the selected issues that each member was interested in at that point. Moreover, they identified the existing obstacles and limitations. Finally, participants cooperatively formulated their important operational plans that consisted of realistic possibilities with the potential to be implemented or supported by members in each group.

According to preschool language development promotion using the family-driven mechanism by FDC staff, the management and partnership participation of both government public sectors and family networks should be considered. The FSC was an experiential learning setting designed to stimulate active adaptation to turbulent environments. The workshop content is based on positive psychology focusing on generating shared images of desirable futures of the group members as a goal for implementation and has been used in a wide variety of contexts. Therefore, the FSC will help to achieve common goals that all members accept, creating clear working guidelines, and enhancing the commitment of members to cooperate in implementing the plan or approach of the group towards commonly agreed upon goals (Noppakesorn, 2014; Williams, 1979; Emery, 1995).

The result of this study was in line with the study of Dewey that explored the future of human resource development using FSC for one profession (Dewey \& Carter, 2003). Furthermore, many studies have applied FSC as a method to develop action plans especially in health organisations. One Thai research project focused on FSC concerning the personal identity basis of the district health system network in Uttaradit Province. The findings revealed that the use of FSC techniques to create the future cooperatively was successful in terms of enabling the participants to gain a clear understanding of the past and to think positively regarding current problems (Injai, Tana, \& Kluanklad, 2015). The participants could develop their desired future plans that were practical to implement. Moreover, one study in Norway revealed that a search conference was used to develop evidence-based health promotion action plans. With its use of both bottom-up and top-down approaches, this method proved a relevant strategy to involve community members in the planning stages of health promotion actions in line with political expectations of participation, ownership and evidence-based initiatives (Magnus, Knudtsen, Wist, Weiss, \& Lillefjell, 2016). The success of the FSC depends on all participants involved sharing ideas and practicing with each other and then implementing more widely. This is consistent with several studies revealing strategies and actions arising from FSC which co-produced dialogue conditions among the stakeholders, leadership strength and participative merger (Babroglu, Topkaya, \& Ates, 1996; Polanyi, 2001; Large, 1998). Even through the search conference has come to be regarded as a critical intervention strategy within interorganizational domains, several external and internal factors pertaining to the search conference may influence the outcomes (Williams, 1979; Babroglu, Topkaya, \& Ates, 1996).

\section{Conclusions}

The FSC as a method could be applied to develop evidence-based professional development action plans to enhance FDC's capacity. This technique involves visualising the learnings from the past, raising awareness of the current situation and creating future strategies to promote early childhood language development in both policy and practice implementation as illustrated below.

Recommendations for policy implication, Support for policy implications should be provided from the ministry, provincial and local levels. Encouraging continuous self-improvement training, enhancing motivation and morale by supporting with an adequate budget, sufficient equipment and reasonable compensation should be a concerned commitment. Furthermore, recognising the importance of being a member of the FDC team in the community is a significant incentive for solving family problems in the community.

Recommendations for practical implications, FSC conference employs the capacity building approach aimed to enhance FDC competency through a participatory learning process. Action plans arising from FSC may be 
valuable as guidelines to develop the capacity of FDC staff to meet the needs within the context of the community and lead to future sustainable solutions. For further research, the critical issues raised by this research included 1) developing knowledge and skills necessary for the operation, 2) promoting group processes and teamwork among the various partners and 3) encouraging motivation to work in a consistent manner.

\section{Acknowledgements}

This article is sponsored by the Mahidol University Alumni Association and Institute of Health Workforce Development. Authors wish to acknowledge grateful appreciation to all research assistants and participants for being actively involved in this study, this research to its successful completion.

\section{References}

Babroglu, O.N., Topkaya, S., \& Ates, O. (1996). Post-search Follow-up: Assessing Search Conference Based Interventions in Two Different Industries in Turkey. Concepts and Transformation, 1(1), 31-50. https://doi.org/10.1075/cat.1.1.04bab

Cheepsumon, Y., \& Boonmak, P. (2014). Lesson learned: Family Development Center in Community: Change in Thai family context (1st ed.) Chandech P, editor. Bangkok: Klakao Inspiration Co., Ltd.

Dewey, J. D., \& Carter, T. J. (2003). Exploring the Future of HRD: The First Future Search Conference for a Profession. Advances in Developing Human Resources, 5(3), 245-256. https://doi.org/10.1177/1523422303254627

Emery, M. (1995). The power of community search conferences. The Journal for Quality and Participation, 18(7), 70.

Injai, M., Tana, S., \& Kluanklad, S. (2015). The Future Search Conference on Personal Identities Basis of The District Health System Network in Uttaradit Province. Journal of Community Development Research (Human and Social Science), 8(1), 122-133.

James, L. (2015). The importance of oral language and its implications for early years practice: A report to Goodstart Early Learning. Newcastle University. Retrieved from https://www.goodstart.org.au/getmedia/8cd15601-203c-441a-a54f-61 caccb4eb22/The-importance-of-oral-la nguage-and-its-implications-for-early-years-practice.pdf.aspx

Janoff, S., \& Weisbord, M. (2021). Future Search USA: Future Search Network. Retrieved from http://www.futuresearch.net/

Kanpirom, K., \& Masena, P. (2017). Survillance for Chilldren Delopment in Age group 0 -5 years, Region Health provider, The Office of Permanent Secretary, Ministry of Public Health. Region 4-5 Medical Journal, 36(4), 305-316.

Large, M. (1998). Using the search conference for planning a merger participatively. Career Development International, 3(2). https://doi.org/10.1108/13620439810207554

Maggi, S. et al. (2005). Knowledge Network for Early Child Development: Analytic and Strategic Review Paper International Perspective on Early Child Development: Human Early Learning Partnership. College for Interdisciplinary Studies, University of British Columbia.

Magnus, E., Knudtsen, M. S., Wist, G., Weiss, D., \& Lillefjell, M. (2016). The search conference as a method in planning community health promotion actions. Journal of Public Health Research, 5(621), 60-67. https://doi.org/10.4081/jphr.2016.621

Maneerat, N. (2008). Developmental strategies of the community family development center: A case study of Kron Subdistrict Administrative Organization, Sawee district, Chumporn province [Master of Public Administration in Local Government]. Kon Kaen: Kon Kaen University.

McDonald, M. (2010). Building the capacity of professionals through post-qualification development and training. CAFCA Practice Sheet.

Medrano, Tabben, \& Toussaint. (2012). Manual 2: Guidelines and Programming Options for Protecting Vulnerable Children in Community-based Care and Support Programs FHI 360 Child Protection Toolkit. McGill D, editor. Research Triangle Park, New York City: FHI 360.

Ministry of Public Health, Thailand [MOPH]. (2015). Early childhood development promotion project of the celebrations on the auspicious occasion of Her Royal Highness Princes Maha Chakri Sirindhorn's 5th cycle Birthday Anniversary 2nd April 2015. Nonthaburi: Beauro of Inspection and Evaluation, Ministry of 
Public Health.

MSDHS. (2010). Future Search Conference (F.S.C.) Manual. Bangkok: Ministry of Social Development and Human Security.

Nopmaneejamruslert, K. (2013). Quality of Children's Life 2013 (1st ed.). Tripathi S, Musikaphan W, editors. Appa printing group, Nakornpathom. The National Institute for Child and Family Development, Mahidol University, Salaya, Nakornpathom, Thailand.

Noppakesorn, T. (2014). Future Search Conference (FSC): Research skill enhancement project by using FSC approach. Phitsanulok, Thailand. Faculty of Social Science, Naresuan University.

Polanyi, M. (2001). Toward common ground and action on repetitive strain injuries: An assessment of a Future Search Conference. The Journal of Applied Behavioral Science, 37(4), 465-487. https://doi.org/10.1177/0021886301374005

Sayre, R., Devercelli, A., Neuman M., \& Wodon Q. (2015). Investing in Early Childhood Development. Washington DC, USA: International Bank for Reconstruction and Development/ The World Bank.

Schmeer, K. (1999). Guidelines for Conducting a Stakeholder Analysis Section 2. November. Retrieved from https://www.who.int/workforcealliance/knowledge/toolkit/33.pdf

Sellnow, R. (2006). Future Search Conference in Theory and Practice. Conference on Public Communication and Large-Scale Urban Regeneration Projects; 5 - 6 September 2006; Poland.

Suphot, D., Nartrudee, D., Pilin, I., \& Kanokrakha, N. (2016). Strong Family and Conflict between work and family in The Globalization. Faculty of Social Sciences and Humanities, Mahidol University.

Tran, T. D., Luchters, S., \& Fisher, J. (2016). Early Childhood development: Impact of National Human Development, Family Poverty, Parenting practices and access Early Childhood Education. Child: Care health and development, 43(3), 415-426. https://doi.org/10.1111/cch.12395

Wake, M. et al. (2012). Improving outcomes of preschool language delay in the community: Protocol for the Language for Learning randomized controlled trial. BMC Pediatrics, 12(96), 1-12. https://doi.org/10.1186/1471-2431-12-96

Williams, T. A. (1979). The Search Conference in Active Adaptive Planning. The Journal of Applied Behavioral Science, 15(4), 470-483. https://doi.org/10.1177/002188637901500403

\section{Copyrights}

Copyright for this article is retained by the author(s), with first publication rights granted to the journal.

This is an open-access article distributed under the terms and conditions of the Creative Commons Attribution license (http://creativecommons.org/licenses/by/4.0/). 